\title{
Analysis of environmental pollution in Sundarbans
}

\author{
Awal Mohd Abdul \\ Environmental Scientist; Founder \& President of Health \& Pollution Research Farm, Long Island City, New York, USA
}

\section{Email address:}

abdul_awal2004@yahoo.com

\section{To cite this article:}

Awal Mohd Abdul. Analysis of Environmental Pollution in Sundarbans. American Journal of Biomedical and Life Sciences. Vol. 2, No. 5, 2014, pp. 98-107. doi: 10.11648/j.ajbls.20140205.11

\begin{abstract}
The Sundarbans is the largest, biologically richest, and most extensive mangrove forest in the world, which is also a world heritage site. Heritiera fomes (Sundri) tree is the most important ecologically dominant and economically valuable tree species and there are 3.5 million in Sundarbans. However, heavy metal contamination is affecting millions of the trees \& people in Sundarbans (Awal, 2007). 45.2 million of Sundri trees have been affected in Sundarbans (Chaffey et, al., 1985). Heavy metals are natural constituents of the earth's crust, and accumulation of heavy metals in soil is responsible for pharmacological activity in plants. Prolonged exposure to heavy metals such as $\mathrm{Al}, \mathrm{As}, \mathrm{B}, \mathrm{Ba}, \mathrm{Bi}, \mathrm{Ca}, \mathrm{Cd}, \mathrm{Co}, \mathrm{Cr}, \mathrm{Cu}, \mathrm{Fe}, \mathrm{Hg}$, In, K, Mg, Mo, Mn, Na, Ni, P, Pb, Rb, Sb, Sc, Se, Si, Sn, Sr, Ti, V, Y, Zn, can cause deleterious health effects in humans \& plants. Excessive levels can be damaging to the organism. Heavy metals disrupt metabolic functions and they accumulate and thereby disrupt function in vital organs and glands such as the heart, brain, kidneys, bone, liver, etc. They displace the vital nutritional minerals from their original place, thereby, hindering their biological function. There are many ways by which these toxins can be introduced into the body such as consumption of foods, skin exposure, and the inhaled air. Plants experience oxidative stress upon exposure to heavy metals that leads to cellular damage and disturbance of cellular ionic homeostasis. So, the loss of $H$. fomes \& loss of surrounding people will have a major impact on the Sundarbans mangrove ecosystem, as well as lead to economic losses. Despite various hypotheses as to the causes of this top-dying, the underlying causes are still not well understood. The present work has explored some of the possible factors involved, focussing particularly on the relationship between the amount of top-dying in different places and the concentrations of a number of chemical elements present in the soil and water and human bodies, in order to test the hypothesis that chemical pollution might be responsible.
\end{abstract}

Keywords: Causal Factors, Heavy Metals, Heritiera Fomes, Mangrove, Sundarbans, Human Health-Problems, Ecological Pollution, Environmental Pollution, Top-Dying

\section{Introduction}

The Sundarbans is the largest single tracts of mangrove forest in the world with 10,029 km2 (Christensen, 1984; Seidensticker and Hai, 1983; Hussain and Karim, 1994). The total area of the part of Sundarbans in Bangladesh is now about 6017 km2 (Imam, 1982; Christensen, 1984; Chaffey et al., 1985). The Sundarban mangrove forest is located mainly at the southern portion of the Gangetic delta bordering on the Bay of Bengal of Bangladesh (Blasco, 1977; Naskar 1999; and Bakshi, 1954; Thom, 1982). The forest lies just south of the topic between $21^{\circ} 38^{\prime}-22^{\circ} 30^{\prime}$ North latitudes and $89^{\circ} 0^{\prime}$ $90^{\circ} 0^{\prime}$ East longitudes.

\subsection{Importance}

Sundarbans is recognised for its ecological importance, for example as the prime habitat of the Royal Bengal Tiger and its importance for local inhabitants. The Sundarbans mangrove forest in Bangladesh is biologically a very rich one, and provides a critical habitat for a diverse marine and terrestrial flora and fauna, and acts as a natural wind break, protecting low lands of the Khulna division and other parts of the country along with 3.5 million surrounding people, with their resources, from hurricanes, tidal surges and natural catastrophes. Also, several hundred thousand people of Bangladesh and India depend directly for their livelihood upon the Sundarbans (Field, 1995).

Sundarbans is the breeding ground for juvenile fish, crabs, shrimps, and mollusks, and is also a prime nesting site for hundreds of birds, animals, reptiles, insects, and species of micro organism.

Mangrove ecosystems therefore provide a unique and valuable range of resources and services. Thus a great 
number of birds, mammals, fishes and invertebrates utilize mangroves like Sundarbans during at least one part of their life cycle (Siddiqi et al., 1993)

\subsection{Sundri Tree}

The main tree species is Heritiera fomes ('Sundri') which is part of a genus that comprises of 29 species and are distributed throughout India, Bangladesh , Burma, Malaysia, New Guinea, the pacific region, tropical Australia and Africa, Heritiera fomes occurs in the Sundarbans, down the coasts of Burma and over large areas of the Asian sub-continent (Chowdhury, 1984). Sundri has a limited bio-geographic distribution, and seedlings do not establish themselves except under specific condition (Curtis, 1933).

\subsection{Symptoms of Top-Dying Disease}

Top-dying or dieback leads to the death of Sundri (Heritiera fomes) trees and consequently Top-dying to the decline of Sundri in the Sundarbans. This condition starts with a decline or death of foliage and twigs in the upper part of the tree, and gradually the symptoms extend downward. This gives a stag-headed condition to the affected trees (Gibson, 1975). Sporadic or patchy occurrence of top dying of Sundri was mentioned early on by Troup (1921). An inventory by Chaffey et al., (1985) revealed that there were about 45.2 million top dying trees in the Sundarbans of which 20 million had more than $50 \%$ of their crown affected by top dying.

\section{Method}

Nine plots were selected for sampling of soil, water, and vegetation in order to categories different areas in terms of their intensity of top-dying. 63 soil samples and 9 water samples were tested, mainly by ICPMS, to investigate certain parameters of the soil and water, such as Sn, Exchangeable K Soil $\mathrm{pH}, \mathrm{Pb}, \mathrm{Zn}, \mathrm{Ni}$, soil $\mathrm{pH}, \mathrm{CEC}$, soil nutrients, soil moisture content, and elemental concentrations of 32 other elements. Most of the elements studied had no significant correlation with the top dying of Heritiera fomes. However, $\mathrm{Sn}$, Exchangeable $\mathrm{K}$, and soil $\mathrm{pH}$ were significantly related (Awal, 2009), and three elements, namely $\mathrm{Pb}, \mathrm{Zn}, \mathrm{Sr}$, were also close to significance.

\subsection{Questionnaire Survey of Local People}

In order to establish the views of local people about the health problems \& the incidence as well as causes of topdying, a questionnaire was prepared for asking peoples either individually or in groups.

\subsection{Evidence of New Health Problems of People Living in or Around the Sundarbans}

As well as seeking evidence about the health status of the Sundarbans, the questionnaire attempted to assess whether there were increasing health issues for the local people resident in the area of Sundarbans. According to the below table, people thought that several human health problems are present among the neighboring peoples of Sundarbans areas. These included particularly skin irritation, black spots on organs of their bodies such as hands and on arms, as well as spots on their faces, dysentery and diarrhea, and cholera problems. They thought that excessive abnormal concentrations of metals, with Arsenic being particularly mentioned and also excessive salinity, were responsible for these diseases (Awal, 2014).

Table 1.0. Summary of the health issues raised by respondents associated with the Sundarbans.

\begin{tabular}{ll}
\hline Health issues raised & Number of times raised \\
\hline Arsenic problems. & 2 \\
Ground water problem. & 1 \\
Skin complaints (irritation or dark spots). & 16 \\
Allergy problems. & 2 \\
Diarrhea. & 6 \\
Dysentery. & 2 \\
Fevers. & 3 \\
Stomach complaints. & 2 \\
Cholera. & 2 \\
Eye problems. & 1 \\
Hair graying. & 1 \\
No idea / unknown. & 28 \\
Other new diseases (unspecified) & 1 \\
\hline
\end{tabular}

This survey was done among people living or working in the 17 Sub-Districts of Sundarbans, making a distinction between those living within and outside of Sundarbans. They were asked whether they had seen the top-dying disease of Heritiera fomes (Sundri) in Sudarbans for a long time, either through living within the Sundarbans or through visiting Sundarbans for their daily work, for their professional work such as forestry officials, for fishing or for collecting wood as wood cutters, for seasonal honey collection, or other purposes.

Groups were made up among targeted people in all locations and from all categories mentioned above, based on age, profession, and also for their sharp memory. In this way, 50 questionnaires were filled up through interview, mostly of groups and sometimes of individual people. The justification of selection of people for the questionnaire survey was that the targeted people were familiar with the top-dying problem in Sundarbans, and are related through their professions with Sundarbans directly and indirectly. The questionnaire started by establishing that the respondents were familiar with common human health problems \& top-dying, as well as went on to seek their views and information on what changes they had observed and whether they had noticed possible causes. This was possible because, most of the interviewees are living within the Sundarbans for their daily activities. So, this survey was performed to receive their indigenous response and knowledge towards top dying and its present conditions, and their ideas about what leads to top-dying, as 
well as questions about tree regeneration and human health in Sundarbans.

Out of 50 responses, 46 answered that top-dying disease of Sundri has increased over time in Sundarbans (Figure.1). This near unanimity provides clear evidence that the problem is getting very noticeably worse over time.

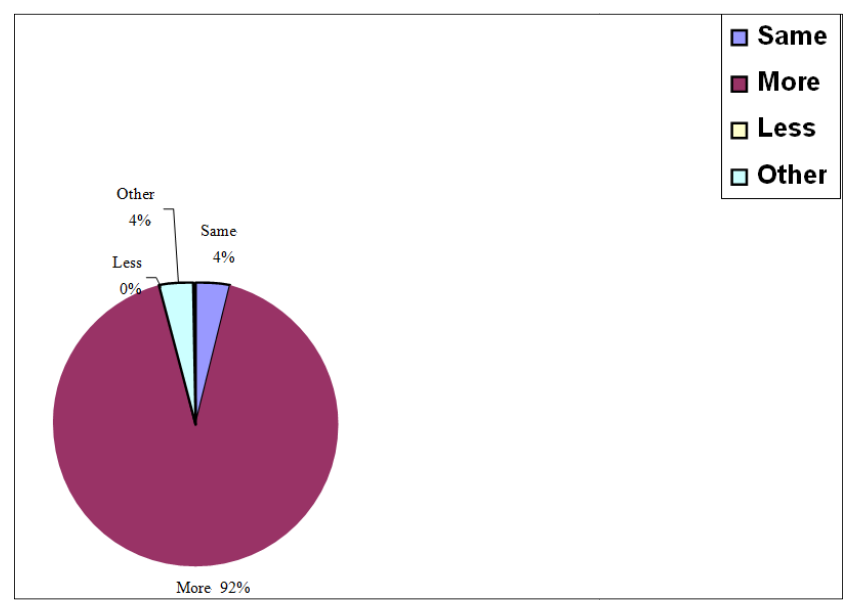

Figure 1.0. Responses to question 2 about the changes observed in topdying over time.

\subsection{Field Sampling Methods}

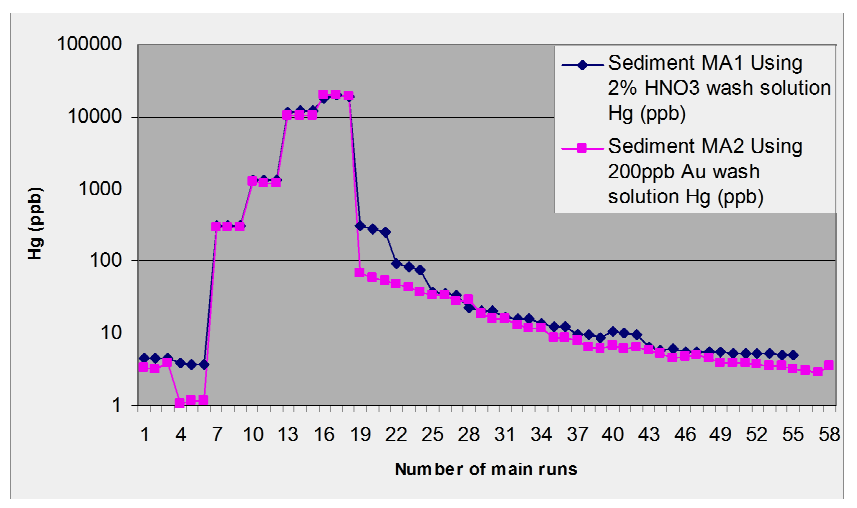

Figure 2.0. Output from ICP-MS analysis of $\mathrm{Hg}$.

Fieldwork was performed between October 2003 and March 2004. Sampling was from the area of the Sundarbans near Chandpai, which is the area most accessible to people and also potentially the one that is most polluted. Three areas (termed 'compartments') from this region were selected (numbers 26, 28 and 31) because they were believed to represent a range of severity of top-dying disease as well as of human activities, as outlined in Awal et al. (2009). Within each of the three compartments, sampling of vegetation, mangrove sediment and water took place within three $20 \mathrm{~m} \mathrm{x}$ $20 \mathrm{~m}$ plots, chosen to reflect a range of top-dying intensities (high, medium and low for that area). The sampling was conducted in a randomised block design, in that a plot was sited within a particular top-dying intensity block, but the precise location of that plot was randomised so as not to bias the detailed data collection. Therefore a total of nine plots were sampled. It should be noted that the material making up the mangrove sediments will include marine, coastal and freshwater deltaic sediments as well as biological material such as tree litter-fall. The relative importance of these sources will depend to a great extent on the patterns of river discharge (Dyer, 1986) and the extent of tidal inundation, and will also therefore vary spatially throughout the Sundarbans.

From each of the nine plots, one water sample was collected in a plastic bottle from a nearby river, creek or channel. Also, seven sediment samples were collected per plot; one from the centre of the plot, four (one each) from all the corners, and two from the middle sides of the plot. Therefore a total of 63 sediment samples were taken. These mangrove sediment samples were collected from $0-30 \mathrm{~cm}$ depth by using a stainless steel spatula and steel cylinder $(d=5.25 \mathrm{~cm})$, and all samples were kept in sealed plastic bags until sample preparation took place. Samples were preserved in portable coolers until arrival at the laboratory at Dhaka University for initial chemical analysis and air drying. This field sampling method followed the W.H.O, U.K, and E.P.A systems of standard laboratory and field sampling principles, rules and regulations. The dried samples were later transported to Bradford, U.K., for chemical analysis by ICP-MS.

Within each of the nine $20 \mathrm{~m} \times 20 \mathrm{~m}$ plots, each adult tree of all species was assessed for three parameters. The diameter at $1 \mathrm{~m}$ height was recorded (in $\mathrm{cm}$ ) by using a measuring tape or slide calipers, depending on girth. The tree height to the top of the crown was determined mainly by ocular estimation, but some heights were checked by using clinometers at a set distance of $20 \mathrm{~m}$ to test the accuracy of such ocular estimations. Thirdly, the status of the tree in respect of the amount of topdying was assessed by using a four point qualitative scale of intensity, namely; not affected, mildly affected, moderately affected or highly affected by top-dying. This was later expressed as a semi-quantitative or rank scale and used as an index of top-dying intensity in that plot.

After assessing the adult trees, the total number of seedlings (individuals of the tree species $<1 \mathrm{~m}$ tall), and saplings (young trees $>1 \mathrm{~m}$ tall with a diameter of trunk of < $10 \mathrm{~cm}$ ), of all species were counted within the plots. Care was taken to ensure that trees, saplings and seedlings were not counted more than once or missed in the recording process by marking them, using different colours for adult and regenerating trees.

\subsection{Laboratory Analyses}

Initial chemical and physical properties of the mangrove sediment samples and the water samples were determined at Soil, Water, \& Environment Department in Dhaka University. These were the electro-conductivity for the determination of sediment and water caution exchange capacity; the $\mathrm{pH}$ of both sediment and water; the percentage moisture content of the sediments; soil particle analysis determined by a Plunger Hydrometer; the concentrations of $\mathrm{S}$, soluble $\mathrm{N}$ (digestion method), and total $\mathrm{N}$ (Kjeldahl method). All remaining elemental concentrations were determined using Inductively Coupled Plasma - Mass Spectrometry (ICP-MS) at Bradford University, England (UK). 


\subsection{Electro-Conductivity}

Fifty $\mathrm{ml}$ of distilled water was added to the sediment, and the mixture shaken mechanically and then stirred 5-7 times to ensure thorough mixing. The sediment suspension was left overnight for it to reach its stable suspension position phase. Finally water EC was recorded by using an EC meter.

\section{6. $p H$}

The $\mathrm{pH}$ of the sediment samples was measured by adding $50 \mathrm{ml}$ of distilled water to [how much?] the sediment, then shaken and stirred 5-7 times to ensure thorough mixing. The mixture was left overnight for it to reach its stable suspension position phase before recording the $\mathrm{pH}$ using a $\mathrm{pH}$ meter. For the $\mathrm{pH}$ of the water samples, $50 \mathrm{ml}$ each of water sample and distilled water were taken, stirring was done in the same way as for the sediment $\mathrm{pH}$ measurement, and the sample solution left overnight before filtering using a Whatman No. 42 filter paper and then recording the $\mathrm{pH}$ as above.

Particle size analysis: Each sediment sample was air dried, ground to a powder, sieved, then reacted with hydrogen peroxide solution $\left(\mathrm{H}_{2} \mathrm{O}_{2}\right)$, according to the procedure described in Black et al. (1965). In the hydrometer, the blank reading was taken after 40 seconds, and the second reading after two hours, maintaining the temperature at $29^{\circ} \mathrm{C}$; and these values were used to calculate the particle size (Black et al., 1965).

Percentage moisture content of the sediment: Approximately $50 \mathrm{~g}$ of sediment was passed through a $2 \mathrm{ml}$ sieve. The sieved material was then weighed and heated to $105^{\circ} \mathrm{C}$ for 24 hours to dry it completely. The dry sediment was then reweighed and the difference in weights gave the weight of moisture. This amount of moisture was expressed as a percentage of the original wet sediment weight.

\subsection{Elemental Concentrations by ICP-MS}

Initial sample preparation was performed at Dhaka University. Adhering materials were removed with forceps, and all sample materials were dried at ambient temperature and were disaggregated to pass a laboratory test sieve using a brush. Soil samples were ground by an acid proof porcelain mortar pestle using a porcelain hammer. After making the soil into powder, samples were kept in plastic bags until later analysis.

Subsequent analyses of the dried sediment samples were performed at Bradford University. In all steps of soil sample preparation and analysis, care was taken to avoid contamination. All items of equipment were first washed by hot tap water, soapy water, cold water, then by deionised water or distilled water and finally with acid leached in deionised water. For drying, all items were kept for 12 hours in an oven, and then they were washed again by the same procedure before storing, to be washed again immediately prior to starting a new analysis. Instruments were cleaned with appropriate blanks before beginning every experiment.

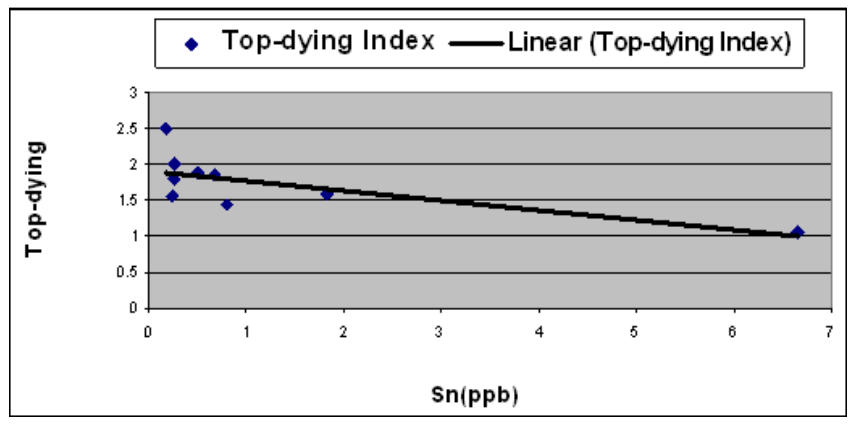

Figure 3.0. Scatter diagram shows the correlation between $S n$ (ppb) and Top-dying index values in the three compartments (26, 28 and 31) sampled in the Sundarbans, with three plots in each compartment.

The 63 samples, together with two reference materials (namely peach leaf, 1547 NIST, and estuarine sediment, 1646 NBS) and blanks as controls were prepared by adding $4 \mathrm{ml}$ of concentrated $1 \mathrm{M} \mathrm{HNO}_{3}$ solution to $0.2 \mathrm{~g}$ of the sample and pre-digested until the reaction of volatile or easily oxidised materials had subsided. Fresh blank samples were made for each separate set of acid digestions. Soil samples were digested by a Microwave Digestion System (MDS). All samples and solutions of material were kept in a cool room (at approximately $5^{\circ} \mathrm{C}$ ) until they were used for analysis. The samples were then sealed in Advanced Composite Vessels with a rupture membrane and pressure control cover in each, and heated in a microwave oven. The samples were heated slowly up to $103^{\circ} \mathrm{C}$, maintaining 175 psi pressure for 12 minutes. The resultant digest was cooled and collected by washing seven times with double-distilled water, filtered, then transferred to a volumetric flask and diluted to make 250 $\mathrm{ml}$ volume.

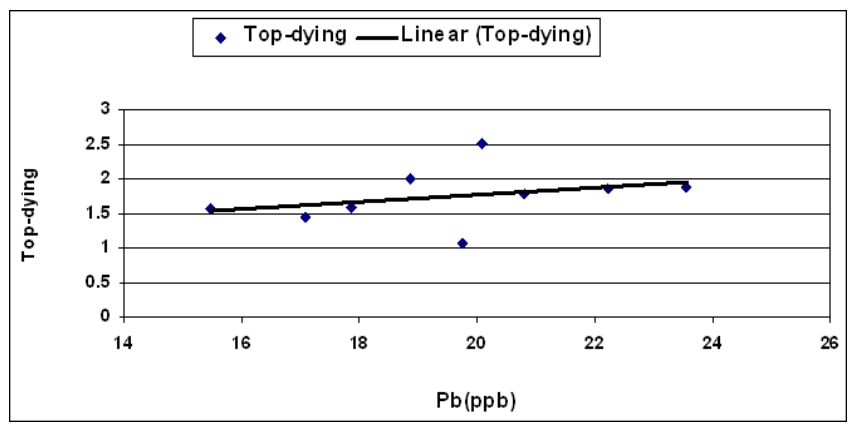

Figure 4.0. Scatter diagram shows the correlation between $\mathrm{Pb}(\mathrm{ppb})$ and Top-dying index values in the three compartments (26, 28 and 31) sampled in the Sundarbans, with three plots in each.

The samples were then analysed for 32 elements, this paper focusing on $\mathrm{Al}, \mathrm{As}, \mathrm{B}, \mathrm{Ba}, \mathrm{Bi}, \mathrm{Ca}, \mathrm{Cd}, \mathrm{Co}, \mathrm{Cr}, \mathrm{Cu}, \mathrm{Fe}$, $\mathrm{Hg}, \mathrm{In}, \mathrm{K}, \mathrm{Mg}, \mathrm{Mo}, \mathrm{Mn}, \mathrm{Na}, \mathrm{Ni}, \mathrm{P}, \mathrm{Pb}, \mathrm{Rb}, \mathrm{Sb}, \mathrm{Sc}, \mathrm{Se}, \mathrm{Si}, \mathrm{Sn}$, Sr, Ti, V, Y, Zn, using ICP-MS. Calibration standards were required for checking the detector response, and these were prepared with known quantities of the elements at five concentrations $(1,10,100,200$ and $1000 \mathrm{ppb})$ to cover the range of concentrations likely to be found for each element. 


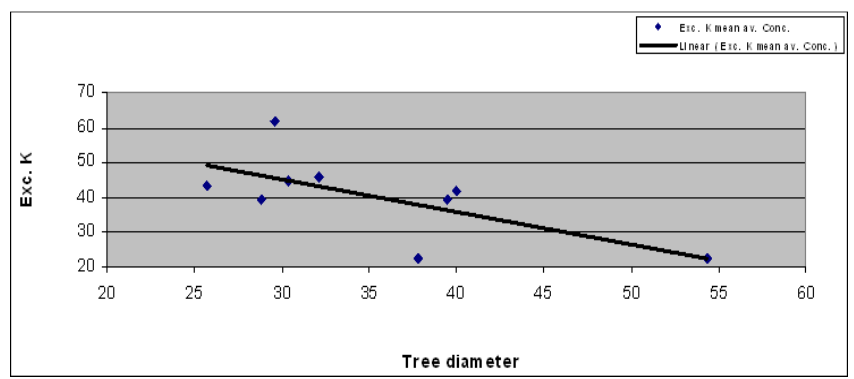

Figure 5.0. Scatter diagram shows the correlation between mean average Exc. $K$ and mean average tree diameter.

The calibration standards are typically prepared using $2 \%$ $\mathrm{HNO}_{3}$, but early trials suggested that there might be retention and cross-contamination of $\mathrm{Hg}$ within the equipment using this acid, and therefore $200 \mathrm{ppb}$ gold-wash solution was used instead which improved instrumental response (details in Awal, 2007). It alloys easily with many metals, such as gold, silver, and tin. These alloys are called amalgams.

Metallic mercury is used in a variety of household products, such as barometers, thermometers and fluorescent light bulbs. The mercury in these devices is trapped and usually does not cause any health problems. However, when a thermometer will break a significantly high exposure to mercury through breathing will occur for a short period of time while it vaporizes. This can cause harmful effects, such as nerve, brain and kidney damage, lung irritation, eye irritation, skin rashes, vomiting and diarrhoea. Moreover, mercury has a number of effects on humans, such as disruption of the nervous system, damage to brain functions, DNA damage and chromosomal damage, allergic reactions, resulting in skin rashes, tiredness and headaches, negative reproductive effects, such as sperm damage, birth defects and miscarriages, and damaged brain functions can cause degradation of learning abilities, personality changes, tremors, vision changes, deafness, muscle in coordination and memory loss. Chromosomal damage is known to cause mongolism. Moreover, Triethyltin is the most dangerous organic tin substance for humans. It has relatively short hydrogen bonds. When hydrogen bonds grow longer a tin substance will be less dangerous to human health. Humans can absorb tin bonds through food and breathing and through the skin. The uptake of tin bonds can cause acute effects as well as long-term effects. Acute effects are: Eye and skin irritations, headaches, stomachaches, sickness and dizziness, severe sweating, breathlessness, urination problems and the long-term effects are depressions, liver damage, malfunctioning of immune systems, chromosomal damage, and shortage of red blood cells, brain damage (causing anger, sleeping disorders, forgetfulness and headaches.)

\subsection{Statistical Analysis}

Data on the severity of top-dying for each tree in a plot, which had been recorded as ' not affected', 'mildly affected', 'moderately affected', and 'highly affected', were converted into a four-point scale (0-3), so that they could be summed and an average (median) could be determined for each plot, thus producing an average index score per plot based on ranked data.

Comparisons of the strength of relationship between two variables were assessed by correlation: the Pearson's product-moment correlation coefficient where both variables were fully quantitative or the Spearman's rank correlation coefficient where the top-dying index was one of the variables. In the case of the Spearman's coefficient, the probability of the outcome was determined by using the approximation to a t-statistic appropriate to these tests (Sokal and Rohlf, 1981). The Spearman's correlation was used here because the top-dying data are based on an index, and probably not meeting all the assumptions of truly parametric data, although since the elemental concentrations are fully quantitative data, using this statistic will result in some information loss.

Data on frequencies of seedlings or saplings in each of the plots and compartments were tested by $\chi^{2}$ contingency table analyses to determine whether the amount of top-dying was associated with location. A similar consideration of the different compartments as comprising one factor, and the plot type as a second, was used to test the pattern of elemental concentrations and other variables by a two-factor analysis of variance test with replication. This allows an assessment of the significance, not only of the two factors separately but also of the interaction between the two factors (Zar, 1984). It should be noted that the plot type was not a strictly controlled factor, since the three categories of top-dying intensity were relative to each other within any one compartment and might not have been exactly equivalent between the three categories in different compartments; interpretation of the results from these test therefore needs to bear this in mind. MINITAB version 14 Statistical Software has been used for all data analysis.

\section{Result}

But, the present results have showed that $\mathrm{Sn}$, Exchangeable $\mathrm{K}, \mathrm{Pb}, \mathrm{Sr}$ and $\mathrm{Zn}$ could be directly linked with top-dying of Heritiera fomes (Sundri) in Sundarbans, probably particularly by weakening the vigour of the trees and allowing other factors such as pathological agents to attack the plants.

The concentrations found in the areas sampled showed most heavy-metal contaminants not to have excessively high concentrations compared to other badly-affected mangrove areas which have previously been investigated.

Notably, however, the elements nickel and mercury appeared to have particularly high concentrations. Furthermore, certain other elements showed significant variations in their concentrations between different parts of the mangrove forest that were sampled near Mongla Port in Bangladesh. Co-relation analyses between the concentrations of the metals and an index of top-dying provided some indications of possible causes of top-dying. 
Table 2.0. Of the hypotheses previously put forward to explain top-dying, the present results do not support enhanced salinity as the cause. It is likely that several of the above-mentioned environmental factors interact with each other to induce top dying in Sundri.

\begin{tabular}{|c|c|c|c|c|}
\hline $\begin{array}{l}\text { Identified heavy-metals } \\
\text { in Sundarbans. }\end{array}$ & $\begin{array}{l}\text { Minimum mean } \\
\text { values (in ppb) }\end{array}$ & $\begin{array}{l}\text { Maximum mean values ( in } \\
\text { ppb) }\end{array}$ & $\begin{array}{l}\text { Minimum mean values (in } \\
\text { ppb) }\end{array}$ & Maximum mean values ( in ppb) \\
\hline $\mathrm{Al}$ (Aluminium) & 15.62 & $37,570.00$ & (Min I): 3.13 & (Min I) 46.10 \\
\hline As (Arsenic) & (-) 0.57 & 10.06 & $\begin{array}{l}0.00006(\mathrm{Pl}) \\
0.00005(\mathrm{Nig})\end{array}$ & $\begin{array}{l}\text { (ES): } 0.0116 \\
0.00111 \text { (Nig) }\end{array}$ \\
\hline B (Boron) & 4.81 & 77.21 & 0.029 (SRM) & (GGC):10.00 \\
\hline $\mathrm{Ba}($ Barium $)$ & 0.41 & 141.80 & $\begin{array}{l}0.124(\mathrm{Pl}) \\
0.011(\mathrm{E} . \mathrm{W})\end{array}$ & $\begin{array}{l}\text { (GGC): } 1.00 \\
2.973 \text { (E.W) }\end{array}$ \\
\hline Bi (Bismuth) & (-) 0.01 & 0.74 & - & $(\mathrm{GGC}): 10.00$ \\
\hline $\mathrm{Ca}($ Calcium $)$ & 44.77 & $17,600.00$ & 0.00005 (E.W) & (GGC):200.0 \\
\hline $\mathrm{Cd}$ (Cadmium) & 0.14 & 1.62 & $\begin{array}{l}0.002 \text { (Thai) } \\
\text { (PI)0.00003 } \\
\text { (Min I):0.0003 }\end{array}$ & $\begin{array}{l}0.016 \text { (Thai) } \\
\text { (ES): } 0.0004 \\
\text { (Min I): } 0.014\end{array}$ \\
\hline Co (Cobalt) & 5.93 & 143.6 & (Min I): 0.003 & $\begin{array}{l}\text { (ES): } 0.0105 \\
\text { (Min I): } 0.026\end{array}$ \\
\hline Cr (Chromium) & 3.14 & 114.90 & 0.0000016 (Nig) & $\begin{array}{l}\text { (ES): } 0.076 \\
0.000017(\mathrm{Nig})\end{array}$ \\
\hline $\mathrm{Cu}$ (Copper) & 1.85 & 43.76 & $\begin{array}{l}0.131 \text { (Thai) } \\
\text { (Pl): } 0.004 \\
\text { (Min I): } 0.006\end{array}$ & $\begin{array}{l}0.260 \text { (Thai) } \\
\text { (ES): } 0.018 \\
\text { (Min I): } 0.086\end{array}$ \\
\hline $\mathrm{Fe}$ (Iron) & 25.82 & 248200.0 & $\begin{array}{l}16.00 \text { (Thai) } \\
\text { (PL): } 0.218 \\
\text { (Min I): } 5.30\end{array}$ & $\begin{array}{l}48.00 \text { (Thai) } \\
\text { (Min I): } 52.00\end{array}$ \\
\hline Hg (Mercury) & $(-) 1.43$ & 83.30 & $\begin{array}{l}0.029 \text { (Min I) } \\
\text { (PL): } 0.00003 \\
0.000023(\mathrm{Nig})\end{array}$ & $\begin{array}{l}0.089 \text { (Min I) } \\
(\mathrm{ES}): 0.00007 \\
0.03(\mathrm{Nig})\end{array}$ \\
\hline In (Indium) & 0.15 & 8.84 & 0.00005 (E.W) & - \\
\hline K (Potassium) & 186.50 & 7495.00 & - & - \\
\hline $\operatorname{Mg}$ (Magnesium) & 5.14 & 18280.00 & - & $(\mathrm{GGC}): 10.0$ \\
\hline Mo (Molybdenum) & 0.20 & 26.15 & $\begin{array}{l}\text { (PL): } 0.00006 \\
0.000008 \text { (Nig) }\end{array}$ & $0.00005(\mathrm{Nig})$ \\
\hline Mn (Manganese) & 0.70 & 698.00 & $\begin{array}{l}\text { (PL): } 0.098 \\
\text { (Min I): } 0.005\end{array}$ & $\begin{array}{l}\text { (ES): } 0.375 \\
\text { (Min I): } 0.44\end{array}$ \\
\hline $\mathrm{Na}$ (Sodium) & 75.83 & 6065.00 & $\begin{array}{l}\text { (PL): } 0.024 \\
0.3()\end{array}$ & $(\mathrm{GGC}): 500.0$ \\
\hline Ni (Nickel) & 7.58 & 1127.00 & $\begin{array}{l}\text { (PL): } 0.0007 \\
\text { (Min I): } 0.008\end{array}$ & $\begin{array}{l}\text { (ES):0.032 } \\
\text { (Min I): } 0.04 \\
\text { (GGC):5.00 }\end{array}$ \\
\hline P (Phosphorus) & (-) 62.83 & 1094.00 & - & $(G G C): 20.0$ \\
\hline $\mathrm{Pb}$ (Lead) & 0.32 & 34.19 & $\begin{array}{l}0.032 \text { (Thai) } \\
\text { (PL): } 0.0009 \\
\text { (M in I): } 0.0015\end{array}$ & $\begin{array}{l}0.079 \text { (Thai) } \\
\text { (ES):0.0282 } \\
\text { (Min I): } 0.024\end{array}$ \\
\hline Rb (Rubidium) & 0.15 & 76.19 & $\begin{array}{l}\text { (PL): } 0.0197 \\
0.02 \text { (E.W) }\end{array}$ & 0.0209 (SRM) \\
\hline $\mathrm{Sb}$ (Antimony) & $(-) 0.23$ & 2.92 & $\begin{array}{l}0.00003(\mathrm{Nig}) \\
0.0005(\mathrm{E} . \mathrm{W})\end{array}$ & $\begin{array}{l}0.000107(\mathrm{Nig}) \\
0.00002(\mathrm{SRM})\end{array}$ \\
\hline Sc (Scandinium) & $(-) 1.15$ & 8.98 & 0.0003 (E.W) & 0.00004(SRM) \\
\hline Se (Selenium) & $(-) 2.98$ & 5.71 & $\begin{array}{l}\text { (PL): } 0.00012 \\
0.00003(\mathrm{Nig})\end{array}$ & $\begin{array}{l}0.00013(\mathrm{SRM}) \\
0.0014(\mathrm{Nig})\end{array}$ \\
\hline Si (Silicon) & $(-) 2033.0$ & 3978.00 & - & $(\mathrm{GGC}): 50.0$ \\
\hline Sn (Tin) & $(-) 0.41$ & 9.68 & $<0.0002(\mathrm{SRM})$ & $(\mathrm{GGC}): 10.0$ \\
\hline $\mathrm{Sr}$ (Strontium) & 0.18 & 44.17 & $(\mathrm{PL}): 0.053$ & $\begin{array}{l}\text { (GGC): } 1.00 \\
0.057 \text { (SRM) }\end{array}$ \\
\hline Ti (Titanium) & 1.37 & 1350.00 & 1.0 (E.W) & $(\mathrm{GGC}): 0.30$ \\
\hline V (Vanadium) & 0.09 & 42.41 & $\begin{array}{l}\text { (PL):0.0004 } \\
0.004(\mathrm{Nig})\end{array}$ & $\begin{array}{l}\text { (ES):0.094 } \\
0.298(\mathrm{Nig})\end{array}$ \\
\hline Y (Yttrium) & 0.03 & 16.69 & $\overline{(\mathrm{PL})}: 0.0179$ & $\begin{array}{l}27000.00(\mathrm{E} . \mathrm{W}) \\
(\mathrm{ES}): 0.138\end{array}$ \\
\hline Zn (Zinc) & 2.30 & 112.60 & $\begin{array}{l}\text { (Min I): } 9.64 \\
0.029 \text { (Thai0 }\end{array}$ & $\begin{array}{l}\text { (Min I):56.2 } \\
0.088 \text { (Thai) }\end{array}$ \\
\hline
\end{tabular}




\section{Discussion}

Comparing figures in the table 2, it would suggest that about two thirds of the elements have concentrations which are elevated compare to other reference sources in the Sundarbans. This would be consistent with the evidence that heavy metals were having an influence on top-dying intensity and human health hazards. The elements $\mathrm{Pb}, \mathrm{Sn}$, and $\mathrm{Zn}$ were highlighted earlier, and although not all of them quite reached statistical significance, the positive trend linking two of them to topdying suggests a likely mechanism of influence, namely that greater concentration of the heavy-metal weaken the resistance of the tree to attack by the pathogenic fungi. This might well be a process that other elements contribute to as well, but has not been picked out by the analysis as showing a link because of the variability between samples inherent in the data. In this respect, the anomaly of the negative relationship indicated for $\mathrm{Sn}$ is harder to explain, but a possible process might be an antagonistic response of $\mathrm{Sn}$ and another element, so that when $\mathrm{Sn}$ is less abundant the other element can have a stronger (deleterious) effect on the trees, thus allowing more top-dying to occur which was highlighted earlier. A further point is that variations in soil $\mathrm{pH}$ from site to site (shown to be significant) will also have a marked effect on the bio-availability of some of these heavy metals, and thus perhaps influence top-dying and human health. Because humans may be exposed to nickel by breathing air, drinking water, eating food or smoking cigarettes. In case of skin contact with nickel-contaminated soil or water may also result in nickel exposure. In small quantities nickel is essential, but when the uptake is too high it can be a danger to human health. An uptake of too large quantities of nickel has bad effects such as higher chances of development of lung cancer, nose cancer, larynx cancer and prostate cancer, sickness and dizziness after exposure to nickel gas, lung embolism, respiratory failure, birth defects, asthma and chronic bronchitis, allergic reactions such as skin rashes, mainly from jewellery, heart disorders.

It is noted that nickel fumes are respiratory irritants and may cause pneumonitis. Exposure to nickel and its compounds may result in the development of a dermatitis known as "nickel itch" in sensitized individuals. The first symptom is usually itching, which occurs up to 7 days before skin eruption occurs. The primary skin eruption is erythematous, or follicular, which may be followed by skin ulceration. Nickel sensitivity, once acquired, appears to persist indefinitely.

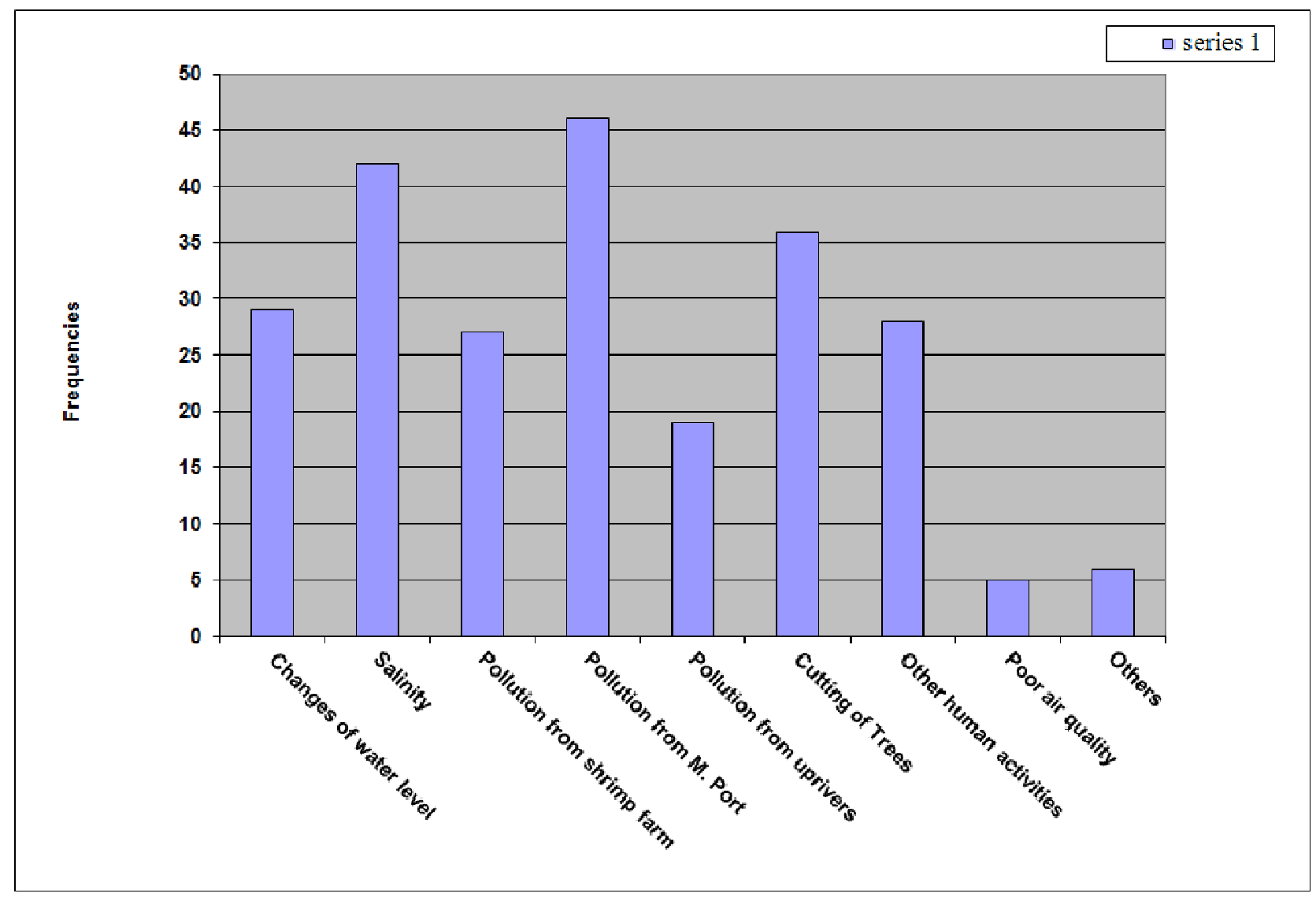

Figure 6.0. Causes of top-dying, as suggested by questionnaire respondents. 
The frequency of responses is indicated in the above figure. According to the respondants, the most likely cause of topdying was from pollution of the water from the Mongla port. The present data also contribute evidence regarding other suggested hypotheses for the causes of top-dying (outlined earlier). The non-significant relationship between soluble or exchangeable $\mathrm{Na}$ and the amount of top-dying, or with the amount of tree growth, strongly suggests that the hypothesis of salinity changes being the cause of top-dying is not correct. However, the data on moisture content percentage do indicate that the Sundarbans has lower values than many other mangrove forests, and the values obtained are rather low even compared to others obtained from the Sundarbans (Faizuddin, 2003). This suggests that the Sundarbans is experiencing problems with its water supply, which may be linked, at least in part, to the construction of the Farraka barrage (FAO report, 1984). If the drainage system of the water basin is poor, the tendency towards more acidic soil and water may increase (Christensen, 1984).

The evidence presented in this paper therefore points not to one specific factor as being entirely responsible for the increasing amount of top-dying and human health problems, but rather to a combination of factors; changing water supply and heavy metal contamination in particular, coupled with possible $\mathrm{pH}$ changes, lead to a weakening of the trees and people, which are then more susceptible to greater attack by pathogens and lowered resistance to them by the trees. This combination of factors is also supported by the comments of the people interviewed, who suggested many different factors as the cause as well as implying that the change was gradual by not being able to pick out a specific starting date to the problem. This would be precisely the pattern that might be expected where no one factor was solely responsible, and the combinations of factors might be somewhat different in different areas. Of course, having a number of interlinked factors as believed likely causes of the problem makes a solution to the problem more difficult. Some suggestions for ways of alleviating the problems, as well as further research that could be done are included in the section below. Although there were only a few individual chemical elements which showed significant correlations with the amount of top-dying, there was evidence of elevated heavy-metal concentrations of many elements in the Sundarbans, which are likely to contribute to the increase in top-dying observed. There were also significant differences between different areas in the Sundarbans, and evidence of water supply problems to the system. Therefore, it is concluded that several factors are responsible for this increase in top-dying, rather than one specific factor only.

\section{Conclusion}

- Although there were only a few individual chemical elements which showed significant correlations with the amount of top-dying, there was evidence of elevated heavy-metal concentrations of almost 14 elements out of 33 tested elements in the Sundarbans, which are likely to contribute to the increase in topdying of Sundri and also health problems observed.

- There were also significant differences between different areas in the Sundarbans, and evidence of water supply problems to the system. Therefore, it is concluded that several factors are responsible for this increase in top-dying of flora and fauna, rather than one specific factor only.

\section{Acknowledgements}

My research work was supported financially by the Peoples' Republic of Bangladesh and the Asian Development Bank (ADB), whom I thank. Particular thanks are due to the ADB head office, Manila for their support and help. I thank sincerely Dr. W.G.H. Hale (Principal Supervisor), University of Bradford, UK, Professor Mike Ashmore (Technical Supervisor), University of York, UK and Dr. P.J. Hogarth for their advice and comments on the work; Dr. Ben Stern and the staff at the Analytical Centre, Bradford, for their help with the ICPMS analyses; Professor Sirajul Hoque, Mustafa (lab Technician)and staff at Dhaka University for providing facilities; and staff of the Forestry Service, Bangladesh Government, for field assistance. Moreover I indebted to my most respected grandfather Munshi Bellal Hossain Bisaw (landlord), most venerated Athaher Hossain, Muktar (land lord), and my grandmother Rahima Khatun, Alimunnessa, my esteemed maternal uncles: Aftabul Azim, Azijul Azim, Anowarul Azim, Aminul Azim, Amirul Azim, Aslam Shehir, and my beloved parents ( Munshi Aowlad Hossain, Mrs. Ashrafunness), Abdur Razzak, Abdur Rouf (Loton), Noorjahan Begum, Kolimuddin, Jamat Ali Mollah, Sadeka Begum,Motiar Rahman (Muntu) my beloved wife (Dr. Shahanaj Khatun), my son (Munshi Tasneem Redowan), my daughter (Marwa Ashra), my beloved brothers (Munshi Abul Kalam Azad), and (Munshi Abdus Salam) and my 6 sisters (Layla Anjumand Banu (Chandu), Akter Rashida Banu (Turi), Saleha Pervin (Lili), Azmeri Ferdowsi (Dolly), Jannatul Ferdowsi (Polly) and my beloved youngest sister Bedowra Ferdowsi (Jolly), Chappa, Chondona, Rono, Sultana, Urfa, Joytun, Loti, Alta, Oysorjo, Omio, Alia, Abdul Khalek, Dilu, Salauddin, Abdul Malek, as well as all family members for their inspiration and help.

\section{References}

[1] Allen, S.E., Grimshaw, H.M., Parkinson, J.A. \& Quarmby, C. (1974) Chemical analysis of ecological materials. Blackwell Scientific Publications, Oxford. (cited in Hoq et al., 2002).

[2] Awal, M.A. (2007). Analysis of possible environmental factors causing top-dying in mangrove forest trees in the Sundarbans in Bangladesh. PhD thesis, University of Bradford.

[3] Awal, M.A., Hale, W.H.G. \& Stern, B. (2009). Trace element concentrations in mangrove sediments in the Sundarbans, Bangladesh. Marine Pollution Bulletin, 58(12), 1944-1948. 
[4] Awal, M.A. (2014). "Correlation between the chemical composition of the surface sediment and water in the mangrove forest of the Sundarbans, Bangladesh, and the regeneration, growth and dieback of the forest trees and people health". Journal of Science Innovation; 2014. 2(2): pp.11-21.Science Publishing Group, USA; May 20th, 2014(2):11-21; doi: 10.11648/j/si.20140202.11.

[5] Black et al (1965) Methods of soil analysis (part 1): physical and mineralogical properties, including statistics of measurement and sampling, pp. 562-566. American Society of Agronomy Inc., Madison, Wisconsin, USA.

[6] Blasco, F., Bellan, M.F. \& Chaudhury, M.U. (1992) Estimating the extent of floods in Bangladesh using SPOT data. Remote Sensing of Environment, 39(3), 167-178.

[7] Blasco, F., Saenger, P. \& Janodet, E. (1996) Mangroves as indicators of coastal change. Catena, 27, 167-178.

[8] Chaffey, D.R., Millar, F.R. \& Sandom, J.H. (1985). A forest inventory of the Sundarbans, Bangladesh, Main Report. Project Report No. 140, 196pp, Overseas Development Agency, London, U.K., pp. 195-196.

[9] Davis, J. \& Freitas, F. (1970). Physical and chemical methods of soil and water analysis. Soils Bulletin 10. FAO, Rome. (cited in Ellison et al 2000)

[10] Dyer, K.R. (1986). Coastal and estuarine sediment dynamics. John Wiley \& Sons, Chichester.

[11] Ellison, A.M., Mukherjee, B.B. \& Karim, A. (2000) Testing patterns of zonation in mangroves: scale dependence and environmental correlates in the Sundarbans of Bangladesh. Journal of Ecology, 88, 813-824.

[12] Gibson, I.A.S. (1975). Report on a visit to the People's Republic of Bangladesh, 28 February to 1 April 1975. Unpublished Report, Overseas Development Agency, London, 28pp.

[13] Gopal, B. \& Chauhan, M. (2006) Biodiversity and its conservation in the Sundarban mangrove ecosystem. Aquatic Sciences, 68(3), 338-354.

[14] Haque, M.R., Ahmad, J.U., Chowdhury, M.D.A., Ahmed, M.K. \& Rahman, M.S. (2004) Seasonal variation of heavy metals concentration in sediments of the rivers and estuaries of Sundarban mangrove forest. Asian Journal of Microbiology, Biotechnology and Environmental Sciences, 6(2), 175-185.

[15] Hartung, F., Werner, R., Hoque, M.I., Alam, Sk.S., Khan, S., Paul, A.R. \& Mühlbach, H.-P. (1998) Association of phytopathogenic bacteria with top-dying disease of Sundri tree (Heritiera fomes) in Bangladesh. Angewandte Botanik, 72, 4855.

[16] Hoq, M.E., Islam, M.L., Paul, H.K., Ahmed, S.U. \& Islam, M.N. (2002). Decomposition and seasonal changes in nutrient constituents in mangrove litter of Sundarbans mangrove, Bangladesh. Indian Journal of Marine Sciences, 31, 130-135.

[17] Hossain, M.S. (2001). Biological aspects of the coastal and marine environment of Bangladesh. Ocean \& Coastal Management, 44, 261-282.

[18] Iftekhar, M.S. (2006) Conservation and management of the Bangladesh coastal ecosystem: overview of an integrated approach. Natural Resources Forum, 30, 230-237.
[19] Iftekhar, M.S. (2008) An overview of mangrove management strategies in three South Asian countries: Bangladesh, India and Sri Lanka. International Forestry Review, 10, 38-51.

[20] Iftekhar, M.S. \& Islam, M.R. (2004) Degeneration of Bangladesh's Sundarbans mangroves: a management issue. International Forestry Review, 6, 123-135.

[21] Iftekhar, M.S. \& Saenger, P. (2008) Vegetation dynamics in the Bangladesh Sundarbans mangroves: a review of forest inventories. Wetlands Ecology \& Management, 16, 291-312.

[22] Islam, M.L., Alam, M.J., Rheman, S., Ahmed, S.U. \& Mazid, M.A. (2004). Water quality, nutrient dynamics and sediment profile in shrimp farms of the Sundarbans mangrove forest, Bangladesh. Indian Journal of Marine Sciences, 33, 170-176.

[23] Karim (1994) in IUCN report pp. 43-74.

[24] Mitra, A., Chakraborty, R. \& Banerjee, K. (2008) Monthly variation of $\mathrm{Zn}, \mathrm{Cu}$ and $\mathrm{Pb}$ in and around Indian Sundarbans. Proceedings of the National Academy of Sciences of India Section B - Biological Sciences, 78, 234-245.

[25] Matilal, S., Mukherjee, B.B., Chaterjee, N. \& Gupta, M.D. (1986) Studies on soil and vegetation of mangrove forest of Sundarbans. Indian Journal of Marine Sciences, 15, 181-184.

[26] Mukhopadhyay, S.K., Biswas, H., De, T.K. \& Jana, T.K. (2006) Fluxes of nutrients from the tropical River Hooghly at the land-ocean boundary of Sundarbans, NE coast of Bay of Bengal, India. Journal of Marine Systems, 62, 9-21.

[27] Peters, R.L. \& Darling, J.D. (1985). The greenhouse effect and nature reserves. Biological Science, 35, 707-717. (Get a copy for me from the library / online if possible)

[28] Phillips and somebody (1994). Which one is it from the thesis list? Get Phillips \& Gentry 94 from the library: Science 263, 954-958. Then see which one it is!

[29] Prain, D. (1903). Flora of the Sundarban. Records of the Botanical Survey of India. Periodical Expert Book Agency, Delhi, pp. 231-370.

[30] Sarika, P.R. \& Chandramohanakumar, N. (2008). Distribution of heavy metals in mangrove sediments of Cochin estuary. Research Journal of Chemistry and Environment, 12, 37-44.

[31] Sarkar, S.K., Bhattacharya, A. \& Bhattacharya, B. (2003) The river Ganga of northern India: an appraisal of its geomorphic and ecological changes. Water Science and Technology, 48, 121-128.

[32] Siddiqi, N.A., Islam, M.R., Khan, M.A.S. \& Shahidullah, M. (1993). Mangrove nurseries in Bangladesh. Mangrove ecosystems occasional papers, International Society for Mangrove Ecosystems, Japan, pp. 1-14.

[33] Snedaker, S. (1991) Notes on the Sundarbans with emphasis on geology, hydrology and forestry. In: Seidensticker, J., Kurin, R. \& Townsend, A.K. (eds). The commons in south Asia: societal pressure and environmental intensity in the Sundarbans. http://www.smartoffice.com/Tiger/Proceedings.html (in Iftekhar \& Islam 2004) Try to get online.

[34] Sokal, R.R. \& Rohlf, F.J. (1981). Biometry. Freeman, New York.

[35] Tam, N.F.Y., Li, S.H., Lan, C.Y., Chen, G.Z., Li, M.S. \& Wong, Y.S. (1995) Nutrients and heavy-metal contamination 
of plants and sediments in Futian mangrove forest. Hydrobiology, 295, 149-158. (Recheck if worth including)

[36] Thomas, G. \& Fernandez, T.V. (1997) Incidence of heavy metals in the mangrove flora and sediments in Kerala, India. Hydrobiology, 352, 77-87.

[37] UN-ESCAP (1987). Final Report: Volume 2. Coastal environment management plan for Bangladesh, Bangkok, Thailand.

[38] UN-ESCAP (1988). Coastal environment management plan for Bangladesh. Bangkok, Thailand, pp. 7-34.
[39] Vane, C.H., Harrison, I., Kim, A.W., Moss-Hayes, V. \& Vickers, B.P. (2009) Organic and metal contamination in surface mangrove sediments of South China. Marine Pollution Bulletin, 58, 134-144.

[40] Wahid, S.M., Babel, M.S. \& Bhuiyan, A.R. (2007) Hydrologic monitoring and analysis in the Sundarbans mangrove ecosystem, Bangladesh. Journal of Hydrology, 332, 381-395.

[41] Zar, J.H. (1984). Biostatistical Analysis (2 $2^{\text {nd }}$ ed.). Prentice-Hall International, London. (is there a $3^{\text {rd }}$ ed? Ref in MacFarlane et al 2007 is for 1999) 